\title{
A impureza da imagem: estéticas intersticiais entre a fotografia analógica e digital
}

Cesar Baio

Resumo: O texto faz uma análise crítica da imagem digital tendo em vista os percursos e desvios do processo de assimilação da fotografia analógica pela base técnica numérica. Parte-se da filosofia do aparato de Flusser e do conceito de emulação de Foucault para pensar a digitalização ocorrida, na década de 1990, como um projeto industrial que visava, sobretudo, à emulação do analógico pelas tecnologias digitais. Passado esse momento histórico de transformações tecnológicas, uma análise distanciada permite levantar a hipótese de que a imagem fotográfica digital passa a assumir uma posição intersticial, entre a fulguração indicial e os algoritmos computacionais. De acordo com tal perspectiva, esse estado de impureza da imagem se tornaria, então, um elemento potencializador da criação artística, na medida em que abre um novo campo de exploração estética.

Palavras-chave: teoria da imagem; fotografia; arte; imagem digital; Vilém Flusser.

Abstract: The impurity of images: aesthetic interstices between analog and digital photography - A critical analysis is made of the digital image, given the incompleteness of the process of assimilation of analog photography by numerical technologies. Vilém Flusser's philosophical apparatus and Foucault's concept of emulation are employed here to interpret the digitization that occurred in the 1990s as an industrial project that was aimed primarily at the emulation of analog technologies by digital ones. After this historical moment of technological transformations, a detached analysis allows one to hypothesize that the digital photographic image begins to assume an interstitial position between indexical fulguration and computational algorithms. This perspective allows for a better understanding of image production in art, which does not entirely deny the indexicality of photography, but also refuses to ignore other possible contemporaneous modes of existence of the image.

Keywords: image theory; digital image; art; photography; Vilém Flusser.

\section{Introdução}

As câmeras fotográficas que utilizamos hoje, sejam elas profissionais, compactas ou aquelas incorporadas nos dispositivos móveis, mantêm em seus antecedentes 
as investigações desenvolvidas, ainda nas décadas de 1950 e 1960, no Bell Labs ${ }^{1}$ e no National Bureau of Standards. ${ }^{2}$ Na base de tais pesquisas, estava a busca por técnicas de aquisição e processamento de imagens que se desdobraram no scanner e, posteriormente, na digitalização dos sinais eletrônicos captados pelos sensores de vídeo, os primeiros passos para a chamada fotografia digital. Não demorou muito para que tais tecnologias chamassem a atenção, mas foi na década de 1990 que elas se popularizaram no circuito da produção midiática, principalmente por conta do lançamento comercial de equipamentos de digitalização e aplicativos especializados em correção e tratamento de imagens. ${ }^{3}$

Essas foram as primeiras etapas de um projeto industrial que prometia a substituição das tecnologias analógicas, baseadas na mecânica, eletrônica e fotoquímica, pelas digitais. O objetivo final de tal projeto, pode-se dizer, era que os circuitos lógicos e os microprocessadores ocupassem o lugar dos componentes mecânicos e químicos, produzindo imagens com tanta "qualidade" quanto aquelas obtidas por meio das tecnologias anteriores. Tal processo de incorporação de uma mídia por outra poderia ser entendido, assim, segundo o conceito de remediação, concebido por Bolter e Grusin (2000) a partir das ideias de Marshall McLuhan.

Uma análise atenta desse processo pode revelar que, ainda que a imagem resultante da fotografia digital mantenha a indicialidade da imagem fotoquímica, as duas imagens e seus processos de produção são bastante diferentes. Tal constatação deixa evidente que, para compreender a imagem fotográfica, produzida atualmente, é necessário investigar como o processo de digitalização teria modificado o estatuto da imagem fotográfica.

Para tanto, parte-se da hipótese de que a passagem da fotografia analógica para a digital é marcada por um processo de "emulação", no qual a base técnica digital visa assumir o lugar daquela baseada na mecânica e na fotoquímica. O processo de emulação é bastante conhecido nas ciências da computação. Ele se dá quando um sistema (por exemplo, um computador atual) imita determinadas características de funcionamento de outro (por exemplo, um console de Atari), assumindo suas funções e se fazendo passar por ele. Essa é a maneira pela qual um aplicativo pode ser processado por um sistema diferente daquele para o qual foi elaborado.

Embora não tenha ganhado muito destaque nas teorias da imagem digital, a emulação parece ter sido uma das principais estratégias na história da inserção das tecnologias digitais, pois que está por detrás de grande parte das investidas promovidas pela indústria das tecnologias de mediação para a assimilação dos processos de produção e distribuição de imagens.

1 Em 1969, Smith e Boyle (2000) desenvolveram os primeiros dispositivos de captação eletrônica de imagens conhecidos por CCD (Charge Coupled Device).

2 No final da década de 1950, Russell Kirsch e sua equipe desenvolveram um dispositivo de leitura eletrônica de imagens (MITCHELL, 1998).

3 Importantes detalhes desse processo de digitalização foram analisados por Mitchell em seu The reconfigured eye: visual truth in the post-photographyc era, de 1998. O teórico da imagem demonstra a importância que grandes corporações da indústria de aparatos tecnológicos de mediação tiveram no processo de digitalização da fotografia. Essas observações são assumidas no presente artigo para dar corpo à ideia de um projeto industrial. 
A análise que é apresentada neste texto assume a emulação como um conceito-chave para a compreensão da imagem fotográfica contemporânea. Segundo a hipótese aqui levantada, a emulação da fotografia pelo digital coloca a imagem em uma condição singular, que não é da ordem do fotoquímico tampouco do sintético, mas sim, de um estado de existência intersticial entre a fulguração indicial e os processos de sintetização dos algoritmos computacionais.

Tal perspectiva oferece um deslocamento conceitual em relação a outras abordagens teóricas da chamada imagem digital, algo que permite melhor compreender certa produção imagética no campo da arte que não nega a indicialidade fotográfica por completo, mas que também não assume definitivamente os processos de sintetização de imagens, ${ }^{4}$ permitindo especular sobre outros estatutos possíveis para a imagem.

\section{A incompletude da emulação e o efeito analógico}

A emulação refere-se à atividade de se igualar a um outro em algum aspecto determinado para, a partir disso, assumir seu lugar. Segundo a figura da aemulatio, como lembra Foucault (2002, p. 27), a emulação ocorre "por sua reduplicação em espelho". Sua vocação especular confirma que, não por acaso, a palavra emular está relacionada ao termo imago, do latim, do qual também deriva a palavra "imagem". Na emulação, o êmulo existe para assumir o lugar do objeto emulado. Contudo, é preciso notar que o êmulo reflete desse objeto apenas uma parte específica das suas características gerais, estritamente o necessário para se fazer passar pelo outro. Essa metáfora, no entanto, é pontual e não anula as diferenças entre ele e o emulado.

Assim, se fosse possível resumir em uma palavra o que está inscrito por detrás da expressão digitalizar que se difundiu nas últimas três décadas, esta seria emular. Emular o analógico em base técnica digital. Essa é a ideia que fundamenta o projeto de expansão da base técnica digital, que visa assumir o lugar dos aparatos tecnológicos da fotografia, do vídeo e do cinema. De início, essa empreitada parecia simples e visava transferir o modelo conceitual do aparato fotográfico de uma base técnica fotoquímica para outra informacional, em busca de aprimoramentos em sua funcionalidade, tais como a facilidade de distribuição e o barateamento de produção. Uma das metas desse processo era a manutenção da sua transparência, na tentativa de que a emulação permanecesse escondida por uma proposta que objetivava menos uma transformação efetiva do aparato do que uma relativamente simples sofisticação tecnológica. Mas, se toda digitalização poderia ser entendida como a emulação de um aparato técnico analógico, uma análise atenta do que vem ocorrendo no campo das tecnologias de mediação acaba por revelar que esse não é um processo sem consequências.

4 Sobre a imagem sintética, produzida exclusivamente por algoritmos computacionais, ver Couchot (2003). 
O que, no início, parecia ser somente um projeto de atualização tecnológica, com o tempo se tornou algo muito mais complexo. As dimensões éticas e estéticas da imagem passaram por transformações que ultrapassaram qualquer restrição colocada pelo determinismo tecnológico da proposta inicial. Isso porque a emulação mantém sempre algo da ordem da incompletude, e, em maior ou menor grau, também do impreciso e de falho. Como, na emulação, uma parte de um sistema imita e substitui parte de outro sistema, e, como o êmulo não pode se manter totalmente isolado das características da base do sistema emulador, acontece algo como um contágio de um pelo outro. O termo "contágio" deriva das expressões latinas contagion, que se refere a uma comunicação "corpo a corpo", e contingere, que significa "toque de perto". É justamente esse corpo a corpo das materialidades de tecnologias e aparatos que retira o sistema emulador de sua condição de transparência e o revela como parte do sistema emulado. Dessa maneira, então, da emulação resulta algo da ordem do híbrido (CANCLINI, 2000), das passagens (BELLOUR, 1997), um corpo impuro, uma imagem engendrada entre o emulador e o emulado.

Os aparatos resultantes desse processo se tornam, assim, ainda mais complexos, já que assumem características do emulador e do emulado, enquanto suas imagens se contaminam incondicionalmente de uma contradição essencial. A um só tempo, eles mantêm alguns de seus traços anteriores e se transformam em algo de estranho à sua origem, assumindo uma forma de existência intersticial.

Mas, embora a máquina fotográfica passe agora a operar por meio de algoritmos computacionais, o output do aparato ainda oferece imagens que tendem a manter mesma indicialidade daquelas produzidas por máquinas fotoquímicas. Essa característica de tais imagens, que talvez seja o principal fundamento a ser protegido no projeto industrial de emulação, poderia ser entendida então como um efeito analógico presente na fotografia digital. Na tentativa de ainda garantir alguma estabilidade na transparência do processo de emulação, o efeito analógico ironicamente se tornou o principal ponto de contato entre o digital e o fotoquímico.

De fato, bastaram poucos anos para a base técnica digital assimilar praticamente todas as etapas dos processos de produção, pós-produção e distribuição de imagens, mas, apesar de se pautar na proposta de uma tecnologia revolucionária, o projeto de digitalização manteve, na prática, valores bastante conservadores que se deixam ver no argumento comercial de que tudo continua como antes. A começar pela criteriosa manutenção do formato da câmera, botões e regulagens, tudo o que poderia representar uma transformação efetiva na maneira de entender a imagem gerada por meio da tecnologia que surgia foi propositadamente escondido por meio de discursos simplificadores que visavam à fácil assimilação desse projeto pelo mercado de consumo. Com isso, qualquer transformação cognitiva significativa na relação com a imagem e com os aparatos técnicos digitais foi sendo deliberadamente negligenciada pelo projeto industrial. 
A despeito da linearidade e do controle imposto a esse processo, o projeto industrial extrapolou os aparatos originais, adicionando novas linhas de força no conjunto de vetores simbólicos até então estabelecidos. Com isso, transformou-se também a maneira como pensamos, experienciamos e nos posicionamos diante dos aparatos técnicos e das suas imagens. ${ }^{5}$ Uma análise desse projeto em seu estágio atual deixa ver uma série de desvios que não haviam sido calculados. Reconhecer esses desvios, esses erros de cálculo, essas falhas de projeto, que se dão pela impossibilidade de transparência do processo de emulação, implica entender que a fotografia se encontra, assim, nesse meio-caminho entre a analogia e a numerização.

Os computadores que produzem fotografias ainda precisam ter o formato de câmeras analógicas, as imagens continuam sendo entendidas por muitos como representações visuais da luz refletida, mas, em contrapartida, nem as imagens nem os aparatos dão conta de esconder a base técnica digital que lhes confere corpo. Trata-se de um estado de impureza que tem se mostrado bastante potente tanto para aqueles que buscam pensar a imagem fotográfica quanto para os que tentam reinventá-la.

\section{A sutil "digitalidade" da hiper-realidade}

Para o filósofo theco-brasileiro Vilém Flusser, os aparatos técnicos cumprem a função de organizar de maneira automática os elementos pontuais (como raios de luz, por exemplo) de modo a dar-lhes forma, tal como um processo de geração de informação (FLUSSER, 2008). Ao partir do pressuposto que não são necessariamente os dados processados que conferem significado à informação, Flusser defende, sobretudo, quais são as relações estabelecidas no interior do aparato que dão sentido aos dados. O filósofo compreende, assim, a imagem como uma representação que não se refere tanto aos dados (ou à fisicalidade dos objetos do mundo, no caso da fotografia), mas aos valores éticos, estéticos e epistemológicos utilizados no processamento desses dados.

$\mathrm{Na}$ fotografia digital, embora o input (raios luminosos) e o output (imagem) sejam semelhantes aos do aparato analógico, o que acontece dentro da caixa-preta é bastante diferente do que se passa no interior das câmeras fotoquímicas. Se Flusser estiver correto quando diz que o aparato técnico é resultado de uma série diversa de conhecimentos os quais se acumulam ao longo do tempo e ganham materialidade na máquina, é possível concluir que, ao incorporar a base técnica digital, o aparato fotográfico foi sobreposto por uma quantidade enorme de outras camadas de conhecimento, os quais se acumularam na ciência ao longo de muito tempo e que deram origem à computação, à informática,

5 Essa condição é evidenciada nas câmeras acopladas aos mais diversos dispositivos móveis. Apesar de ainda manterem a emulação como um princípio importante em suas interfaces gráficas e operações, esses aparatos instituem sensíveis modificações no modo como lidamos com suas imagens. Exemplos disso são os aplicativos de produção automática de panorâmicas, os algoritmos de identificação de objetos, pessoas e movimento e, principalmente, os recursos de conexão em rede, que permitem que um único aparelho edite, publique, insira comentários críticos e habilite a venda de imagens produzidas por ele próprio. 
às redes de informação, etc. A inserção dessas camadas abstratas tem causado impactos de força suficiente para colocar em cheque o próprio estatuto da imagem fotográfica.

Atentos a isso, a partir do final da década de 1990, muitos artistas passaram a explorar essa condição de instabilidade, visando especular sobre outras possíveis formas de existência para a imagem. Esse é o caso do inglês Paul M. Smith. Em sua série Artist Rifles (1997) ${ }^{6}$, o artista cria cenas do ambiente militar, em suas batalhas e comemorações, sobrepondo seu próprio rosto à face de cada soldado. Com essa proposta, ele chama a atenção para a perda da individualidade no exército e, também, como notou Paul (2004), para o anonimato do poder militar. Como afirma Paul, essa perda da individualidade é problematizada também na multiplicação de identidades proposta por Gerald van der Kaap em 12th of Never (1999) 7 .

Dentro do mesmo campo conceitual, mas operando de maneira reversa, a artista brasileira Helga Stein, criou Andros Hertz $(2004)^{8}$, uma série de autorretratos manipulados digitalmente que multiplicam a imagem da artista em diferentes versões dela mesma. Apesar de manter certos parâmetros em comum, cada imagem mostra um rosto diferente do outro, de modo que é impossível reconhecer traços que revelem a verdadeira aparência da artista.

Diferentemente do que aconteceu anteriormente com o vídeo, o cinema e a própria fotografia, esses artistas não parecem buscar por uma especificidade que negue o analógico em favor do digital. Eles começaram a operar justamente em uma zona impura, mestiça e contaminada, situada entre as duas bases técnicas, levando adiante o que Krauss (1999) definiu como condição pós-midiática. Para isso, eles trazem para a dimensão estética uma problemática que se ergue na contemporaneidade e que coloca em crise a ideia de uma identidade estabilizadora de um sujeito unívoco. Utilizando-se dos mais atuais recursos digitais de pós-produção, eles manipulam suas imagens na tentativa de estruturar comentários que tratem a um só tempo da identidade do sujeito e da própria imagem fotográfica.

Esses artistas criam imagens com a coerência estrutural da perspectiva e o realismo da fotografia, mas que acabam por revelar os códigos dos quais suas imagens são feitas. Como afirma Paul (2004, p. 38), "Estas realidades alternativas criadas pela manipulação digital, além de serem obras tingidas de 'hiper-realidade', são obras que colocam em cena uma realidade aumentada, sublinhada, cuja representação não parece totalmente artificial nem totalmente verdadeira". A ironia presente nesses trabalhos se faz justamente no camuflar da manipulação para revelar certa "digitalidade" da imagem. Elas ressaltam os elementos mais tradicionais do código fotográfico visando revelar algo de natureza outra, que estaria escondido por detrás da linearidade do espaço, dos corpos e da luz. Trabalhos como esses deixam ver que a digitalização pode transformar os próprios aparatos em questão. A fotografia, o vídeo e o cinema tornam-se, em alguma medida, estranhos em relação àquilo que eram. Isso deixa no ar muitas questões em relação à condição da imagem.

6 Disponível em: <http://www.paulmsmith.co.uk/portfolio/artist-rifles/artist-rifles.html>. Acesso em: jun. 2014.

7 Disponível em: <http://www.geraldvanderkaap.com/theworkspages/99002_400.html>. Acesso em: jun. 2014.

8 Disponível em: <https://www.flickr.com/photos/helgastein/sets/72157594172276010/>. Acesso em: jun. 2014. 
Uma reflexão sobre as passagens entre a imagem fotoquímica, a eletrônica e a digital, deixa ver o aumento progressivo do nível de abstração na relação entre a imagem e o mundo. Na primeira escala desse processo está a imagem fotoquímica, que mantém uma estreita relação formal de analogia com o objeto fotografado, de acordo com o que Machado (1984) definiu como ilusão especular.

Ainda que se possa entender que, como defende Flusser, essa relação não torne necessariamente a imagem um índice da realidade mediante a reflexão da luz pelo objeto, esse efeito ilusório é produzido por uma ação direta da luz em uma superfície fotossensível, que é ela mesma o suporte primeiro e definitivo da imagem. Embora a imagem possa ser duplicada, ela está encerrada nesse seu suporte primordial, do qual nunca poderá ser removida sem prejuízo da matriz. Tal processo é marcado por uma grande estabilidade na captura e no armazenamento da imagem, dada justamente pela fixidez do suporte. $\mathrm{Na}$ imagem eletrônica, essa relação concreta com o mundo tende a se tornar mais tênue, uma vez que a câmera de vídeo passa a quantificar os raios luminosos em valores de informação e que a imagem se torna resultado de um processo de escaneamento que se repete trinta vezes por segundo.

Tal como no vídeo, no digital, a imagem já não está mais atrelada irreversivelmente a um suporte físico. Assim como o disco rígido de um computador ou uma memória flash portátil está para o digital, a fita cassete esteve para o vídeo, ou seja, apenas como um local no qual a informação precisa estar temporariamente alocada (DUBOIS, 2004). Entretanto, a base técnica digital eleva o grau de abstração da imagem a uma escala sem precedentes, uma vez que a quantificação da luz passa a ser segmentada e lida em lotes, de acordo com os processos de amostragem (sampling) e quantificação (quantizations).

Tais processos fazem com que o resultado obtido da leitura dos raios luminosos seja um algoritmo matemático que, em si, é incapaz de responder a qualquer analogia com um objeto físico. Uma vez transformada definitivamente em equações matemáticas, a imagem se mistura a tudo o mais que pode ser digitalizado, torna-se informação em fluxo, instável, dinâmica, apenas acessível por processos de cálculo que acontecem no instante de sua atualização na tela. Por outro lado, esse grau extremo de abstração pode conduzir a outro nível de concretude, dado pela pragmática das operações inventivas possíveis sobre o aspecto computacional da imagem.

\section{A imagem e o código}

Um dos desdobramentos da elevação da abstração é o aumento do grau de precisão nos procedimentos de intervenção no interior do aparato. Os controles sobre a captação, o processamento e a distribuição de imagem, que vinham sendo refinados progressivamente com a fotografia, o cinema e o vídeo, com a base digital, chegaram a uma escala nunca antes possível. 
Nesse percurso exploratório, seguem trabalhos como Horror Vaccui (1999) ${ }^{9}$, de Daniel Canogar. O artista espanhol multiplica as partes do seu corpo, embaralhando o branco e o preto de suas impressões digitais com os próprios dígitos numéricos que estão na base dos cálculos dos microprocessadores.

No Brasil, o fotógrafo Guilherme Maranhão tem explorado muito bem essa passagem entre códigos de naturezas diversas. Em sua série Pluracidades (2006), ele faz confundir o movimento e a estaticidade da cidade. A indicialidade análoga se dilui nas operações de digitalização a que ele impõe a paisagem urbana. Ao transformar scanners descartados em câmeras, o fotógrafo estabelece um modo de produção de imagens que faz com que o código visual da fotografia se contamine com os dos fluxos informacionais. Suas imagens conduzem a pensar sobre abstrações de outros níveis, que se deixam ver, por exemplo, nas relações cada vez mais distantes que estabelecemos com a cidade, dada a aceleração do ritmo da vida cotidiana. Como um lugar de passagem, vistas por nós através das janelas de carros, ônibus e trens em velocidade, as ruas e avenidas se tornam paisagens cada vez mais parecidas com as imagens de Guilherme.

Esses trabalhos evidenciam uma das principais características da produção de imagens contemporânea, que é justamente a ampliação exponencial das possibilidades operativas do artista sobre os aparatos de geração de imagens. O termo "operativo", que deriva do latim operativus, significa ao mesmo tempo "criativo e formativo", e, em seu sentido original, quer dizer "produzir o efeito desejado". Assim, com a extrema elevação do grau de controle técnico, a base digital habilita procedimentos operativos jamais disponíveis para a criação e formalização de conceitos em imagens.

A abstração e a operação podem ser, então, tomadas como duas características importantes da base técnica digital, que tornam a imagem programável (MANOVICH, 2001) e, por isso, resultado de operações procedimentais (MURRAY, 2003) que se dão no interior dos algoritmos computacionais e na relação destes com interfaces e com redes de informação. Como resultado de um algoritmo que se distribui nos fluxos de dados, a imagem pode passar a ser concebida como uma imagem em rede (WEIBEL, 2004), elaborada a partir de conexões cíbridas ${ }^{10}$ (BEIGUELMAN, 2004). Se as características da imagem digital forem analisadas em conjunto, seria possível verificar que todas elas se alinham sob o par conceitual abstração «=» abertura à operação inventiva.

Ao pensar a imagem a partir do conceito de aparato, nota-se que esses dois aspectos não foram introduzidos necessariamente pelas tecnologias digitais, como também não são exclusividade delas. No entanto, na base técnica digital, o grau de abstração e de operação torna-se algo sem precedentes. Essa ideia tem inspirado muitos dos artistas a explorar justamente esses aspectos da imagem que a base técnica digital expande, visando investigar possíveis deslocamentos de ordem do estatuto da imagem.

9 Disponível em: <http://www.danielcanogar.com/ficha.php?lang=en\&year=1999\&proyecto=02_horrorvacui>. Acesso em: jun. 2014.

10 Redes on e off-line. 
Ao longo de sua carreira, a brasileira Giselle Beiguelman tem desenvolvido uma pesquisa extensa sobre a condição digital da imagem. Em CodeUp (2004) ${ }^{11}$, uma obra emblemática da artista, Beiguelman cria uma instalação que recebe via bluetooth fotografias feitas com aparelhos celulares enviadas pelos visitantes. Ao ler as imagens, a instalação converte os valores numéricos correspondentes às informações de cada pixel em profundidade espacial (em RGB - R para vermelho, G para verde e B para azul), gerando uma matriz tridimensional de informação.

Inspirada no filme Blow Up (1966), em que Michelangelo Antonioni coloca em pauta o problema da representação na imagem fotoquímica, o trabalho de Beiguelman é uma investigação sobre o modo como a codificação simbólica está relacionada aos processos de construção do sentido e da forma das imagens digitais.

Nesse percurso a indicialidade da imagem se funde com a dimensão simbólica dos códigos que a estruturam, revelando o que há por detrás do efeito analógico. Ao gerar uma matriz digital que preserva parte da figuratividade, ao mesmo tempo que coloca em crise a visualidade fotográfica, o trabalho gera uma demanda cognitiva do público, o qual é chamado a procurar outra forma de compreender a imagem. Para Beiguelman (2010), "As imagens digitais não dizem respeito à natureza, mas a linguagens de programação. Suas cores - um elemento básico da percepção visual - são produzidas por sistemas numéricos, operações lógicas e displays eletrônicos".

Outro artista que tem assumido sistematicamente essa problemática é Andreas MüllerPohle. Em suas séries Digital Scores (after Nicéphore Niépce) ${ }^{12}$ (1995-1998), o artista alemão se apropria de uma das mais antigas fotografias conhecidas ainda existentes para, a partir de sua digitalização, criar imagens alfanuméricas que falam da sua condição digital. Em vez da imagem de Niépce, o que o trabalho deixa ver é apenas um conjunto ininteligível de dígitos. A impossibilidade de entender qualquer aspecto figurativo na imagem acaba por revelar o código que a gerou. Em contrapartida, o artista questiona também a natureza analógica da imagem fotoquímica (e sua suposta analogia aos sentidos humanos).

Como afirma Müller-Pohle (2014), a fotografia de Niépce teve "um tempo de exposição de oito horas e, presumivelmente, nunca poderia, assim, corresponder ao olhar humano". Com isso, o artista toma a experiência com a imagem digital como base para lançar um novo olhar sobre o aparato fotográfico analógico e reinterpretá-lo. Ao assumir que nem mesmo as mais antigas fotografias mantinham relação com um olhar natural, ele reconecta as duas imagens: a digital e a fotoquímica. O mais instigante, no entanto, é que ele o faz explorando justamente as diferenças entre elas.

Ao ampliar o grau de operação sobre a imagem, tais tecnologias expandem as possibilidades de emergência de novas propostas estéticas, de novos regimes de sentido, de novas imagens. A conexão direta e instantânea entre esses controles e os diferentes tipos

11 Disponível em: <http://www.zkm.de/algorithmische-revolution/index.php?module=pagemaster\&PAGE_user_ op=view_page\&PAGE_id=40>. Acesso em: jun. 2014.

12 Disponível em: <http://www.muellerpohle.net/projects/scores.html>. Acesso em: jun. 2014. 
e fontes de informação vinculam a imagem aos mais diversos aparatos de informação e sensoriamento eletrônico, anulando distâncias entre espaços e corpos. Um aspecto que torna mais difícil distinguir a diferença entre imagem e interface, apontando para o que foi concebido por Weibel (2004) como uma imagem em rede.

Entre os artistas que têm pensado essa condição em rede da imagem, está o americano Mark Napier. Em seu Venus 2.0 (2009) ${ }^{13}$, Napier cria uma instalação, que se desdobra em um vídeo e uma série de retratos, todos produzidos por um algoritmo de composição que mistura diversas imagens recolhidas da web por mecanismos de busca da estrela pop Pâmela Anderson. O aplicativo criado pelo artista recorta centenas de imagens, dividindo o corpo da modelo em várias partes e o recompondo em um móbile digital tridimensional. Com a fragmentação da imagem, Napier aponta para uma esquizofrenia do olhar que se multiplica e se divide nas múltiplas janelas, telas e atividades que as interfaces computacionais demandam atualmente.

Por outro lado, o artista propõe transferir a sensualidade da modelo, símbolo sexual mais procurado nos sistemas de busca da web, para a própria tecnologia, representando o fascínio que esta exerce no imaginário contemporâneo. Esse trabalho de Napier coloca em questão a maneira como lidamos e compreendemos a imagem em uma cultura permeada pelas redes de informação. A imagem que se tem ao final não é concebida integralmente pelo artista, a composição é feita também por meio de decisões tomadas por software de modo que, nem mesmo o artista sabe exatamente qual será o resultado. A imagem emerge de um sistema complexo de iterações ${ }^{14}$ parametrizadas que elevam ao extremo as virtualidades da imagem.

De maneira geral, os trabalhos aqui apresentados revelam um deslocamento importante que vem acontecendo no campo abrangente da arte contemporânea. Cada vez mais os artistas têm se desviado das questões formais da imagem para se dedicarem às operações dentro dos aparatos que as produzem. Com isso, esses trabalhos devem ser entendidos não como uma exploração da imagem, como representação do mundo, mas, sim, como investigações sobre esse estado impuro da imagem como um elemento potencializador para explorações estéticas que especulem sobre a possibilidade de outros regimes de sentido da imagem. Eles exploram aspectos não tão evidentes da proposta de digitalização das mídias, propondo uma problematização desse lugar de passagem entre o analógico e o digital. Com essa postura, esses artistas parecem entender o gesto fotográfico tal como Flusser (1994, p. 104) o considerou: como um "gesto filosófico".

É preciso notar que isso instaura uma dobra fundamental no modo de pensar tanto as práticas artísticas contemporâneas quanto a própria imagem. Há um deslocamento da concepção corrente de visualidade rumo à atuação corporal da (e sobre) a imagem. Essa passagem deixa ver que, se for possível pensar em uma mudança no modo de existência

13 Disponível em: <http://marknapier.com/pam>. Acesso em: jun. 2014.

14 Processos computacionais baseados na repetição de cálculos matemáticos. 
da imagem, esta passaria pela reversibilidade do seu regime de sentido. Seu sentido não poderia mais ser analisado tendo em vista um objeto anterior a ela (o referente), mas sim, o modo como essa imagem projeta determinado modelo de conhecimento no mundo, ou seja, o modo como ela afeta e demanda do corpo.

Do ponto de vista das teorias da imagem, compreender esse contexto passaria necessariamente por questionar o que as imagens estariam representando. Elas ainda poderiam ser concebidas como a presença de uma ausência, tal como elas são entendidas pela definição filosófica de representação? Ou a imagem passaria a interessar mais pelo que ela opera com sua atuação no mundo enquanto disparadora de questões e especulações sobre os modelos de conhecimento estabelecidos?

Essa problemática aponta para a urgência em se pensar os regimes de imagem que emergem de tais aparatos digitais no campo da arte. Para tanto, seria preciso entender que, no jogo entre o artista e o aparato, algumas regras mudam e outras permanecem. Mapear esse campo, entender as dinâmicas das transformações em curso, revelar outros modos de pensar e existir da imagem, de acordo com a nova configuração dos vetores que tencionam entre si nas camadas abstratas de tais aparatos é o desafio lançado ao artista, a quem cabe explorar justamente os entre-caminhos desse terreno impuro e apenas inicialmente explorado que é a imagem digital.

Cesar Baio é professor adjunto da Universidade Federal do Ceará; é doutor em Comunicação e Semiótica pela PUCSP, com estágio sanduíche na Universität der Künste Berlin (UDK). Sua pesquisa está voltada para a imagem técnica e os aparatos tecnológicos de mediação.

baio.cesar@gmail.com

\section{Referências}

BELLOUR, R. Entre-Imagens. São Paulo: Papirus Editora, 1997

BEIGUELMAN, G. Entrevista com Giselle Beiguelman. Fórum latino-americano de fotografia de São Paulo, 2010. Disponível em: <http://www.forumfoto.org.br/giselle-beiguelman/>. Acesso em: 10 abr. 2014.

Admirável Mundo Cíbrido, 2004. Disponível em: <https://www.academia.edu/3003787/ Admiravel_mundo_cibrido.>. Acesso em: 10 abr. 2014.

BOLTER, J. D.; GRUSIN, R. Remediation: understanding new media. Cambridge, Massachussets: The MIT Press, 2000.

CANCLINI, N. G. Culturas Híbridas. 3a. ed. São Paulo: EDUSP, 2000. 
COUCHOT, E. A tecnologia na arte: da fotografia à realidade virtual. Tradução de Sandra Rey. Porto Alegre: Editora da UFRGS, 2003.

DUBOIS, P. Cinema, video, Godard. Tradução de Mateus Araújo Silva. São Paulo: Cosac Naify, 2004. (Coleção cinema, teatro e modernidade)

FLUSSER, V. O universo das imagens técnicas: elogio da superficialidade. São Paulo: Annablume, 2008. Los Gestos. Barcelona: Herder, 1994.

FOUCAULT, M. As palavas e as coisas: uma arqueologia das ciências humanas. Tradução de Salma Tannus Muchail. São Paulo: Martins Fontes, 2002.

KRAUSS, R. A voyage on the north sea. London: Thames e Hudson, 1999.

MACHADO, A. A ilusão especular: introdução à fotografia. São Paulo: Brasiliense, 1984.

MANOVICH, L. The language of new media. Cambridge, London, MIT Press, 2001.

MITCHELL, W. The reconfigured eye: visual truth in the post-photographyc era. Cambridge: The MIT Press, 1998.

MÜLLER-POHLE, A. Digital scores, 2014. Disponível em: <http://www.muellerpohle.net/projects/ scores.html>. Acesso em abr. 2014. (site do artista)

MURRAY, J. H. Hamlet no holodeck: o futuro da narrativa no ciberespaço. Tradução de Elissa Khoury Daher, Marcelo Fernandez Cuzziol. São Paulo: Unesp, Itau Cultural, 2003.

PAUL, C. L'art numérique. Paris: Thames \& Hudson, 2004.

SMITH, G. E.; BOYLE, W. The invention and early history of the CCD. In: AMICO, Paola; BELETIC, James W. (eds.). Optical Detectors For Astronomy II: State-Of-The-Art at the Turn of the Millennium. Dordrecht: Kluwer Academic Publichers, 2000.

WEIBEL, P. La imagem inteligente: ¿neurocinema o cinema cuántico? In: Arte Algorítmico. De Cezane a la Computadora. Seminário organizado por UNESCO y MECAD/ESDi, 2004. 